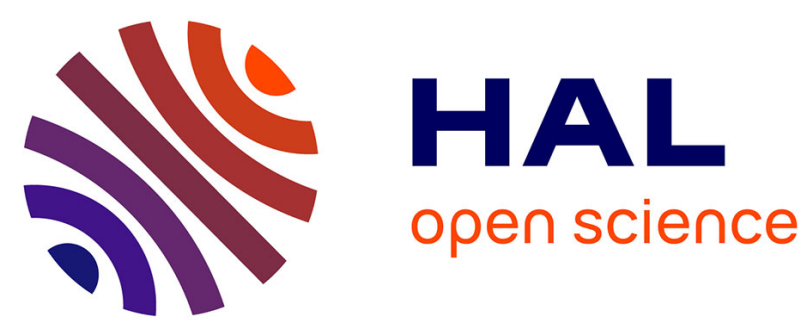

\title{
Low molecular weight fucoidan prevents intimal hyperplasia in rat injured thoracic aorta through the modulation of matrix metalloproteinase-2 expression.
}

Hanna Hlawaty, Nadine Suffee, Angela Sutton, Olivier Oudar, Oualid Haddad, Veronique Olivier, Christelle Laguillier-Morizot, Liliane Gattegno,

Didier Letourneur, Nathalie Charnaux

\section{To cite this version:}

Hanna Hlawaty, Nadine Suffee, Angela Sutton, Olivier Oudar, Oualid Haddad, et al.. Low molecular weight fucoidan prevents intimal hyperplasia in rat injured thoracic aorta through the modulation of matrix metalloproteinase-2 expression.. Biochemical Pharmacology, 2010, 81 (2), pp.233. 10.1016/j.bcp.2010.09.021 . hal-00649891

\section{HAL Id: hal-00649891 https://hal.science/hal-00649891}

Submitted on 9 Dec 2011

HAL is a multi-disciplinary open access archive for the deposit and dissemination of scientific research documents, whether they are published or not. The documents may come from teaching and research institutions in France or abroad, or from public or private research centers.
L'archive ouverte pluridisciplinaire HAL, est destinée au dépôt et à la diffusion de documents scientifiques de niveau recherche, publiés ou non, émanant des établissements d'enseignement et de recherche français ou étrangers, des laboratoires publics ou privés. 


\section{Accepted Manuscript}

Title: Low molecular weight fucoidan prevents intimal hyperplasia in rat injured thoracic aorta through the modulation of matrix metalloproteinase- 2 expression.

Authors: Hanna Hlawaty, Nadine Suffee, Angela Sutton, Olivier Oudar, Oualid Haddad, Veronique Olivier, Christelle

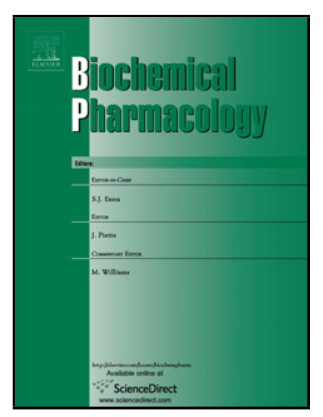
Laguillier-Morizot, Liliane Gattegno, Didier Letourneur, Nathalie Charnaux

PII: S0006-2952(10)00704-5

DOI: doi:10.1016/j.bcp.2010.09.021

Reference: BCP 10726

To appear in: $\quad B C P$

Received date: $\quad 28-7-2010$

Revised date: 20-9-2010

Accepted date: $\quad 22-9-2010$

Please cite this article as: Hlawaty H, Suffee N, Sutton A, Oudar O, Haddad O, Olivier V, Laguillier-Morizot C, Gattegno L, Letourneur D, Charnaux N, Low molecular weight fucoidan prevents intimal hyperplasia in rat injured thoracic aorta through the modulation of matrix metalloproteinase-2 expression., Biochemical Pharmacology (2010), doi:10.1016/j.bcp.2010.09.021

This is a PDF file of an unedited manuscript that has been accepted for publication. As a service to our customers we are providing this early version of the manuscript. The manuscript will undergo copyediting, typesetting, and review of the resulting proof before it is published in its final form. Please note that during the production process errors may be discovered which could affect the content, and all legal disclaimers that apply to the journal pertain. 


\section{Low molecular weight fucoidan prevents intimal hyperplasia in rat injured} thoracic aorta through the modulation of matrix metalloproteinase-2

\section{expression.}

Hanna Hlawaty ${ }^{\text {a,* }}$, Nadine Suffee ${ }^{\mathrm{a}, *}$, Angela Sutton ${ }^{\mathrm{a}, \mathrm{b}}$, Olivier Oudar ${ }^{\mathrm{a}}$, Oualid Haddad ${ }^{\mathrm{a}}$, Veronique Olivier ${ }^{a}$, Christelle Laguillier-Morizot ${ }^{\mathrm{a}, \mathrm{b}}$, Liliane Gattegno ${ }^{\mathrm{a}, \mathrm{b}}$, Didier Letourneur ${ }^{\mathrm{a}}$, Nathalie Charnaux ${ }^{a, b, * *}$

a INSERM U698, Bio-ingénierie cardiovasculaire, Université Paris 13, France

${ }^{\mathrm{b}}$ Laboratoire de Biochimie, Hôpital Jean Verdier AP-HP Bondy, France

* Contributed equally to the work

** Corresponding author:

INSERM U698

Bio-ingénierie cardiovasculaire,

UFR SMBH, Université Paris 13,

74 rue Marcel Cachin,

F-93017, Bobigny

Tel: 33-1-48-02-65-13; Fax: 33-1-48-02-65-03;

E-mail: nathalie.charnaux@jvr.aphp.fr

Short title: Fucoidan Inhibits Intimal Hyperplasia in Rat

Keywords: Fucoidan; intimal hyperplasia; smooth muscle cell; endothelial cell; MMP-2

Abbreviations: LMWF, low molecular weight fucoidan; MMP, matrix metalloproteinase; SDF-1, stromal cell-derived factor-1; VEGF, vascular endothelial growth factor; VSMC, vascular smooth muscle cell 


\begin{abstract}
The therapeutic potential of low molecular-weight fucoidan (LMWF), a sulfated polysaccharide extracted from brown seaweed was investigated on vascular smooth muscle cell (VSMC) and human vascular endothelial cell (HUV-EC-C) proliferation and migration in vitro and in a rat model of intimal hyperplasia. Sprague-Dawley rats were subjected to balloon injury in the thoracic aorta followed by two weeks' treatment with either LMWF ( $5 \mathrm{mg} / \mathrm{kg} /$ day) or vehicle. Morphological analysis and proliferating cell nuclear antigen immunostaining at day 14 indicated that LMWF prevented intimal hyperplasia in rat thoracic aorta as compared with vehicle (neointima area, $3 \pm 0.50$ versus $\left.5 \pm 0.30 \mathrm{~mm}^{2}, P<0.01\right)$. In situ zymography showed that LMWF significantly decreased the activity of matrix metalloproteinase (MMP)-2 in the neo-intima compared to vehicle. The in vitro study demonstrated that $10 \mu \mathrm{g} / \mathrm{ml} \mathrm{LMWF}$ increased HUV-ECC migration by $45 \pm 5 \%$ but reduced VSMC migration by $40 \pm 3 \%$. LMWF also increased MMP2 mRNA expression in HUV-EC-Cs and reduced it in VSMCs. MMP-2 level in the conditioned medium from cells incubated with $10 \mu \mathrm{g} / \mathrm{ml}$ LMWF was 5.4-fold higher in HUV-EC-C, but 6fold lower in VSMCs than in untreated control cells. Furthermore, decreasing MMP-2 expression in HUV-EC-Cs or VSMCs by RNA interference resulted in reduced LMWF-induced effects on cell migration.

In conclusion, LMWF increased HUV-EC-C migration and decreased VSMC migration in vitro. In vivo, this natural compound reduced the intimal hyperplasia in the rat aortic wall after balloon injury. Therefore, LMWF could be of interest for the prevention of intimal hyperplasia.
\end{abstract}

Word count:248 


\section{Introduction}

Cardiovascular disease, due essentially to atherosclerosis, causes a major part of deaths in western countries. The arterial wall consists of three layers: the (inner) intima, the media and the (outer) adventitia. Intimal hyperplasia is the principal mechanism of restenosis after balloon angioplasty, with intimal damage and media overstretch leading to vascular smooth muscle cell (VSMC) proliferation, platelet deposition and leukocyte recruitment [1]. It is currently believed that medial VSMC proliferation and migration, as well as transmigration and retention of blood borne inflammatory cells play roles in the formation of obstructive atherosclerotic lesions. As some attempts to modify the response to arterial injury failed [2,3], an understanding of the patho-physiological process of neo-intima formation, extracellular matrix (ECM) remodeling, and the identification of appropriate cellular or molecular targets for therapeutic treatment are still of interest.

The first response to vascular injury in the rat is a dramatic increase of VSMC proliferation in the media, which occurs 1 to 3 days after injury [4,5]. The second phase of lesion development, beginning at day 3, involves the migration of VSMCs into the intima [6], resulting in neo-intima formation, where VSMCs are normally not found in the rat. During the third phase of lesion development, VSMCs proliferate within the neo-intima [6]. Proliferation and migration of VSMCs lead to intimal hyperplasia, fibrous cap formation and atherosclerosis development [7].

Matrix metalloproteinases (MMPs) play an important role in the pathogenesis of restenosis after arterial angioplasty. They orchestrate ECM degradation, facilitate migration and proliferation of VSMCs leading to neo-intimal development [8]. MMP-2 (gelatinase A, type IV collagenase) is one of the MMP members that has been extensively studied and has been found to 
play an important role in increasing restenosis after either inflammatory or mechanical injury to the vascular wall $[9,10]$. MMP-2 is expressed abundantly in atherosclerotic and restenotic lesions, and the inhibition of its activity by synthetic compounds greatly reduces neo-intima formation [11].

Vascular endothelial cells play an important role in the control of vascular function and present a large surface area for the exchange of materials between blood and tissues. They participate in vascular homeostasis, interacting with circulating cells, on the one hand, and cells present in the vascular wall, VSMCs, on the other hand. In pathological processes, the balance between vascular endothelial cells and VSMCs is disturbed by endothelial activation and dysfunction leading to local inflammation, thrombosis and vasoconstriction [12].

Fucoidan is a sulfated polysaccharide extracted from brown seaweed that reduces rat smooth muscle cell proliferation in vitro in a more intensive manner than heparin [13]. We have previously shown the therapeutic potential of low molecular weight fucoidan (LMWF) in reduction of in-stent restenosis in a rabbit model, vascular tissue repair [14] and in critical hindlimb ischemia in a rat model [15]. Interestingly, LMWF has been shown to release the glycosaminoglycan-bound stromal cell-derived factor-1 (SDF-1)/CXCL12, which mobilizes progenitor cells [16-18] and may participate in angiogenesis with vascular endothelial growth factor (VEGF) and fibroblast growth factor (FGF) [19].

The aim of this work was to evaluate the ability of LMWF to inhibit VSMC mobility and stimulate HUV-EC-C migration in vitro and to assess its in vivo therapeutic effect using a rat model of intimal hyperplasia after balloon injury. 


\subsection{Polysaccharide}

LMWF was isolated and hydrolyzed by a radical depolymerization process [20] from high molecular weight (HMW) extracts of brown marine algae. The characteristics of LMWF according to previously reported analytical methods [21] are as follows: weight average molecular mass $8 \pm 1 \mathrm{kDa}$; fucose content 35\% (wt/wt); uronic acid content 3\% (wt/wt); and sulfate content $34 \%(\mathrm{wt} / \mathrm{wt})$. The anticoagulant activity in vitro of the LMWF has been established by an activated partial thromboplastin time (APTT), and the amount of LMWF required to obtain an APTT of $80 \mathrm{sec}$ (control $40 \mathrm{sec}$ ) was $25 \mathrm{~g} / \mathrm{ml}$ [22].

\subsection{Rat model of intimal hyperplasia in thoracic aorta}

The animal protocol was approved by the Bichat University Institutional Animal Care and Use Committee. Adult male Sprague-Dawley rats $(\mathrm{n}=12,280-300 \mathrm{~g}$, purchased from Janvier, CERJ, Laval, France) were anesthetized with intraperitoneal pentobarbital injection $(50 \mathrm{mg} / \mathrm{kg}$, CEVA Santé Animale, Libourne, France) [15]. A 2F Fogerty balloon catheter (Baxter Healthcare Corporation, Irvine, CA, USA) was inserted through an incision made in the external carotid artery and advanced along the length of the common carotid artery to the thoracic aorta [23]. The balloon was then inflated and passed three times along the length of the aorta. The balloon catheter was removed, the external carotid artery was permanently ligated and the skin wound was repaired. Then, the animals were divided into two groups: the first one received the LMWF solution $(5 \mathrm{mg} / \mathrm{kg} / \mathrm{day}, \mathrm{n}=6)$ and the second one received the saline solution (control animals, $\mathrm{n}$ = 6) via intramuscularly injection (IM) in the right leg for 14 days. The LMWF injections were 


\subsection{Blood analysis and white blood cell count}

Two weeks after balloon injury, the blood samples were harvested and were either centrifuged for ELISA assays, or assayed for determination of blood cell counts (white blood cells, monocytes, eosinophils, basophils, red blood cells, platelets, haemoglobin, hematocrit) or biochemical analysis (creatinine, urea, glucose, aspartate and alanine aminotransferase, triglycerides, total and HDL cholesterol) by an automated Coulter XE 2100 (Beckman Coulter France, Roissy, France) or COBAS 6000 (Roche, Meylan, France).

\subsection{Tissue harvest and histology processing}

Two weeks after balloon injury, rats were killed by pentobarbital overdose. The thoracic aortas were harvested, flushed with saline solution, cleaned of adipose tissue and cut into 4-cm-long tubes. The aortic tubes were divided into two groups. The first one (thoracic, $n=6$ ) was fixed in 4\% para-formaldehyde (Sigma-Aldrich, Lyon, France), embedded in paraffin, and cut in $9-\mu \mathrm{m}-$ thick cross sections for histology study. The second one (thoracic, $n=6$ ) was frozen in liquid nitrogen-cooled isopentane, cut in 9- $\mu$ m-thick cross sections with a Leica CM1900 cryostat (Leica Microsystems, Rueil-Malmaison, France) for immunohistochemistry study. Cell density in the neo-intima was observed under a microscope and analyzed for 10 different sections per group. 


\subsection{Morphological studies}

After fixation in $4 \%$ paraformaldehyde, rat aortas were stained with hematoxylin and eosin solution (Sigma-Aldrich). The intimal and medial areas were quantified using a light microscope (Leica DMRXA microscope, Leica Microsystems) coupled to HistoLab image analysis software (HistoLab Software, Microvision Instruments, Evry, France). Digital planimetry with the use of a video camera mounted on a microscope analyzed the borders of the external elastic lamina, internal elastic lamina, and vessel lumen. Specific software (HistoLab Software) allowed quantification of the neo-intimal, medial, and adventitial areas. Neo-intimal growth was estimated by using the neo-intimal area, medial area and the ratio of intimal to medial areas. At least 3 sections of each stained samples were used for quantification, representing different levels of the arterial segment.

\subsection{Immunofluorescence of carotid artery}

Adjacent 9- $\mu$ m-thick fresh arterial cross sections were immunostained with mouse anti-human endothelium CD31 (rat cross-reactive, clone RECA-1, dilution 1/20; Abcam, Paris, France) and mouse anti-human smooth-muscle $\alpha$-actin ( $\alpha$-SMA) (rat cross-reactive, clone 1A4, dilution 1/100; DAKO Corporation, Carpinteria, CA, USA) as previously described [1]. Afterwards, slides were co-incubated with the appropriate secondary antibodies $(5 \mu \mathrm{g} / \mathrm{ml}$; Invitrogen, Cergy Pontoise, France). Negative control sections were incubated only with the secondary antibodies. Representative immunofluorescence photomicrographs were taken using a Leica DMRXA microscope (Leica Microsystems).

For proliferating cell nuclear antigen (PCNA) immunostaining, cryostat sections were incubated with a mouse monoclonal anti-human PCNA antibody (rat cross-reactive, clone PC10, dilution 
1/200; DAKO Corporation), revealed by incubation with rhodamine-stained goat anti-mouse IgG (dilution 1/100; Invitrogen).

\subsection{Gel in situ zymography}

The frozen tissue disposed above was sliced into $10 \mu \mathrm{m}$ with a cryostat. Then a polyethylene terephthalate-base film coated with $7 \mu \mathrm{M}$ crosslinked gelatin (Wako Pure Chemical industries, Osaka, Japan) was placed on and was incubated for $24 \mathrm{~h}$ at $37^{\circ} \mathrm{C}$ in a humidified chamber. After incubation, the film was stained with $1 \%$ amido black 10B (Wako Pure Chemical industries) in 70\% (v/v) methanol (VWR, Strasbourg, France) and 10\% (v/v) acetic acid (VWR) for $15 \mathrm{~min}$. The film was destained with distilled water, $70 \%(\mathrm{v} / \mathrm{v})$ methanol and 10\% (v/v) acetic acid solution. Lysis of the substrate was assessed by examination under a fluorescent microscope (Zeiss Axiophot microscope, Carl Zeiss France, Le Pecq, France). The specificity of the proteolysis was examined on adjacent serial sections incubated on a film containing the protease inhibitor 1,10-phenanthroline, indicating that the activity was caused by MMPs.

\subsection{Cell culture}

Human Vascular Endothelial Cells (HUV-EC-Cs, N ${ }^{\circ}$ CRL-1730, ATCC, LGC Molsheim, France) were cultured in Endothelial Cell Basal Medium 2 (ECBM2, PromoCell, Heidelberg, Germany) supplemented with 10\% fetal bovine serum, EGF (Epidermal Growth Factor, 5.0 ng/ml), hydrocortisone (0.2 $\mu \mathrm{g} / \mathrm{ml})$, VEGF (0.5 ng/ml), bFF (basic Fibroblast Factor, $10 \mathrm{ng} / \mathrm{ml}$ ), R3 IGF-1 (Insulin like Growth Factor, $20 \mathrm{ng} / \mathrm{ml})$, Ascorbic Acid $(1 \mu \mathrm{g} / \mathrm{ml})$, heparin $(22.5 \mu \mathrm{g} / \mathrm{ml})$, antibiotics (penicillin-streptomycin, $1 \%$, Invitrogen) and L-Glutamine (1\%, Invitrogen) at $37{ }^{\circ} \mathrm{C}$ in $5 \% \mathrm{CO}_{2}$. 
Human Vascular Smooth Muscle Cells (VSMC, PromoCell) were cultured in Smooth Muscle Cell Basal Medium 2 (SMCBM2, PromoCell) supplemented with 5\% fetal bovine serum, hEGF (human Epidermal Growth Factor, 5.0 ng/ml), hbFF (human basic Fibroblast Factor, 2 ng/ml), insulin $(5 \mathrm{ng} / \mathrm{ml})$, antibiotics (penicillin-streptomycin, 1\%, Invitrogen) and L-Glutamine (1\%, Invitrogen) at $37^{\circ} \mathrm{C}$ in $5 \% \mathrm{CO}_{2}$.

The media was changed twice a week. Twenty-four hours before migration, HUV-EC-Cs and VSMCs were plated in 24-well plates at a density of $5 \times 10^{4}$ cells per well and cultured at $37{ }^{\circ} \mathrm{C}$ in $5 \% \mathrm{CO}_{2}$.

As demonstrated [24,25], the presence of growth factors such as VEGF, EGF, bFGF and IGF-1 in the culture medium of both HUV-EC-Cs and VSMCs, mimics the atherogenic conditions in in vitro cultures. For migration, spreading, proliferation of HUV-EC-Cs, heparin was not added to the supplemented basal cell culture medium.

\subsection{Spreading assay}

Spreading of HUV-EC-C or VSMC cells were carried out in respective supplemented basal cell culture media, as previously described [26]. Briefly, serum-deprived cells incubated with LMWF $(0.1,1$ and $10 \mu \mathrm{g} / \mathrm{ml}$ ) were allowed to spread on fibronectin (BD Bioscience Pharmingen, Le Pont de Claix, France) for 2 h. Then the cells were permeabilized in $0.05 \%$ Triton X-100 (SigmaAldrich) and were stained with Alexa Fluor 546 phalloidin (dilution 1/100, Invitrogen) and observed with a fluorescence microscope (Zeiss Axiophot, Carl Zeiss France). Cell areas were evaluated on 30 cells by analysis with the NIH (release Beta $3 b$ ) software (National Institutes of Health). Alternatively, HUV-EC-C cells were transfected either with MMP-2 siRNA-1 or MMP2 siRNA-2 or SNC RNA (Eurogentec, Seraing, Belgium) for $6 \mathrm{~h}$, then washed and supplemented 
endothelial cell medium was added for $24 \mathrm{~h}$. Then, HUV-EC-C cells were allowed to spread on fibronectin for $2 \mathrm{~h}$.

\subsection{Wound migration assay}

The in vitro migratory activity of HUV-EC-Cs and VSMCs was measured using a wound migration assay and performed in respective supplemented cell basal culture media. HUV-EC-Cs and VSMCs (50-70\% confluence) were wounded uniformly using a sterile $1.15 \mathrm{~mm}$ diameter pipette tip. Then, the cells were treated with $\operatorname{LMWF}(0.1,1$ and $10 \mu \mathrm{g} / \mathrm{ml})$ during $24 \mathrm{~h}$, then washed and incubated with respective supplemented cell basal culture media. Standard photographs of the wounded areas were taken using a phase contrast microscopy (Olympus CK40 microscope, X10 objective, Olympus France, Rungis, France) immediately after wounding and then $48 \mathrm{~h}$ after migration (15 images at each time point). Distance between cells at both sides of the wound was measured for 5 pairs of cells per image. The cell migration distance was calculated by subtracting the distance at the lesion edge at $48 \mathrm{~h}$ from the distance measured at $0 \mathrm{~h}$. Then, HUV-EC-Cs were wounded uniformly using a sterile $1.15 \mathrm{~mm}$ diameter pipette tip and photographs were taken $48 \mathrm{~h}$ later.

Alternatively, HUV-EC-Cs were transfected either with MMP-2 siRNA-1 or MMP-2 siRNA-2 or SNC RNA (Eurogentec) for $6 \mathrm{~h}$, then washed and supplemented endothelial cell basal culture medium was added for $24 \mathrm{~h}$. The percentage of inhibition was [(D1-D2)/D1] x 100. D1 was the difference between the number of SNC RNA-transfected cells treated with LMWF and that of untreated SNC RNA-transfected cells. D2 was the difference between the number of MMP-2 siRNA-transfected cells treated with LMWF and that of untreated MMP-2 siRNAtransfected cells. 


\subsection{Cell migration and invasion assays in Boyden chambers}

HUV-EC-C and VSMC migration and invasion assays were performed in respective supplemented cell basal culture media using Bio-coat cell migration chambers (BD Bioscience Pharmingen) [27]. Briefly, inserts were coated with fibronectin $(100 \mu \mathrm{g} / \mathrm{ml}$, BD Bioscience Pharmingen) for migration or Matrigel $(320 \mu \mathrm{g} / \mathrm{ml}$, BD Bioscience Pharmingen) for invasion assays, respectively. Untreated control cells or cells treated with $10 \mu \mathrm{g} / \mathrm{ml}$ LMWF were placed in the upper chamber and allowed to migrate or invade. After twenty-four hours, cells migrated through the porous membrane were stained with Mayer's hemalum (Sigma-Aldrich) and counted manually by two different observers who performed the blind data acquisition.

In order to analyze the influence of conditioned medium from HUV-EC-Cs pre-incubated or not with LMWF on VSMC migration, VSMCs were placed in the upper part of the Boyden chamber and allowed to migrate through fibronectin towards (placed in the lower part of the Boyden chamber): 1- unconditioned endothelial cell supplemented culture medium or 2unconditioned endothelial cell supplemented culture medium in the presence of $10 \mu \mathrm{g} / \mathrm{ml}$ LMWF, 3- conditioned HUV-EC-C supplemented culture medium or 4- conditioned HUV-EC-C supplemented culture medium from HUV-EC-Cs pre-incubated with $10 \mu \mathrm{g} / \mathrm{ml} \mathrm{LMWF}$ for $24 \mathrm{~h}$. The percentage of inhibition was calculated as described [28].

\subsection{Gelatin zymographic assay}

HUV-EC-Cs and VSMCs were treated with $10 \mu \mathrm{g} / \mathrm{ml}$ LMWF. Gelatinolytic activities of proMMP-2 and active MMP-2 were measured in cell conditioned media as previously described [29]. The MMP activities were estimated from the 72 and $66 \mathrm{kDa}$ gelatinolytic bands corresponding to pro-MMP-2 and active MMP-2, as previously described [29]. Densitometric 
analysis of scanned gelatinolytic bands were performed with NIH (release Beta 3b) software. Total MMP activity was defined as the sum of the pro-form and the active form of MMP-2.

\subsection{Assessment of Viability and Cell Proliferation}

Viable adherent HUV-EC-Cs and VSMCs were quantified after LMWF treatment, using a MTT test (Sigma-Aldrich). Untreated cells $\left(3 \times 10^{5}\right)$ or cells pre-treated with $10 \mu \mathrm{g} / \mathrm{ml} \mathrm{LMWF}$ for $24 \mathrm{~h}$, were incubated with $10 \mu \mathrm{M}$ bromo-2-deoxyuridine (BrdU, Invitrogen) for $4 \mathrm{~h}$ for HUV-EC-Cs and $16 \mathrm{~h}$ for VSMCs before cell collection. After BrdU labelling, the cells were washed in PBS, fixed in $1 \%$ paraformaldehyde (Sigma-Aldrich) and permeabilized with $0.05 \%$ Triton X100 (Sigma-Aldrich) for $3 \mathrm{~min}$. The cells were then treated with DNaseI (Sigma-Aldrich) for $30 \mathrm{~min}$ at $37{ }^{\circ} \mathrm{C}$, to expose incorporated BrdU, washed with PBS and stained with Alexa Fluor 647 conjugated anti-BrdU antibody (dilution 1/100, Invitrogen), for $30 \mathrm{~min}$ at room temperature. Flow cytometry analysis was performed and the percentage of BrdU-positive cells was calculated.

\subsection{ELISA assay}

ELISA assay of total MMP-2 level was performed in the conditioned medium from HUV-EC-C or VSMC cells pre-treated with $10 \mu \mathrm{g} / \mathrm{ml}$ LMWF for $24 \mathrm{~h}$. MMP2 Elisa kit (Quantikine Human/Mouse/Rat MMP-2 (total) Immunoassay, DMP200) was purchased from R\&D Systems (Lyon, France).

\subsection{Western blotting}

HUV-EC-Cs and VSMCs were incubated with $10 \mu \mathrm{g} / \mathrm{ml}$ LMWF for $24 \mathrm{~h}$ and assayed for Western blot as previously described [30]. The supernatant was collected and protein 
concentration was determined by bicinchoninic acid (BCA) assay (Pierce Biotechnology, Rockford, USA). Total MMP-2 protein was probed using anti-MMP-2 rabbit polyclonal IgG antibodies (dilution 1/500; Santa Cruz Biotechnology, Heidelberg, Germany) and revealed with horseradish peroxidase (HRP) anti-rabbit immunoglobulin G (dilution 1/2000; Santa Cruz Biotechnology). The gels were then washed and proteins were detected using Enhanced chemiluminescence detection reagents (GE Healthcare, Orsay, France).

\subsection{Real-time RT-PCR and siRNA transfection}

Real-time RT-PCR assays were performed using a Step-One with a MMP-2 TaqMan kit (Applied Biosystem, Courtaboeuf, France). MMP-2 mRNA levels were normalized with two housekeeping gene levels as described in the manufacturer's instructions (TaqMan Inventoried Assay; GAPDH: Hs02758991_g1, $\beta$-actin: Hs00357333_g1, MMP-2: Hs1548724_m1).

Two MMP-2 gene-specific sense and antisense 21-nt single stranded RNAs with symmetric $2 \mathrm{nt}$ 3'(2'-deoxy) thymidine overhangs were designed, chemically synthesized and HPLC purified (Eurogentec). Small-interfering RNA (siRNA) sequences corresponding to MMP-2 were: 5'CAG-GUG-AUC-UUG-ACC-ACC-AGA-AdTdT-3', (reverse) 5'-UUC-UGG-UCA-AGA-UCACCU-GdTdT-3' for MMP-2 siRNA-1 and (forward) 5'-GAC-AAA-UUC-UGG-AGA-UACAdTdT-3', (reverse) 5'-UGU-AUC-UCC-AGA-AUU-UGU-CdTdT-3' for MMP-2 siRNA-2. HUV-EC-Cs or VSMCs were transfected with $100 \mathrm{nM}$ siRNA in serum-free medium using jetSITM-ENDO transfectant reagent (Eurogentec) following the manufacturer's instructions. Mock cells were cultured in parallel and transfected with jetSITM-ENDO lacking siRNA. In each experiment, a SNC RNA (Eurogentec) was used as a negative control. Cells transfected with MMP-2 siRNA-1 or MMP-2 siRNA-2 or SNC RNA or mock-transfected were used 3 days posttransfection for further analysis. 


\subsection{Statistical Analysis}

For the determination of statistical significance, an ANOVA test was performed with the Statview software (StatView 4.5 Abacus Concepts, Berkeley, USA). A $P$ value of $<0.05$ was used as the criterion of statistical significance.

\section{Results}

\subsection{LMWF prevents intimal hyperplasia in balloon-injured rat thoracic aorta.}

Rats were submitted to balloon angioplasty followed by 2 weeks of treatment with saline or LMWF injections. No rat died during the procedures or the 14-day treatment with LMWF (5 $\mathrm{mg} / \mathrm{kg} / \mathrm{day} \mathrm{IM}$ ). Biochemical and haematological blood parameters and organ weight were not different in samples obtained from LMWF-treated versus control animals (data not shown). Histological sections of thoracic aortas that were uninjured (Fig. 1a, left panel) or balloon-injured and vehicle-treated (Fig. 1a, middle panel), or balloon-injured and LMWF-treated (Fig. 1a, right panel) are presented. Morphological analysis indicated that the balloon angioplasty of rat thoracic aortas increased significantly the neo-intimal area of these aortas compared with aortas in uninjured animals ( $5 \pm 0.30$ versus $0.2 \pm 0.02 \mathrm{~mm}^{2}$ respectively, $P<0.01, \mathrm{n}=6$ ), whereas the medial area was not different (Table 1). The neo-intimal area in the aortas was significantly reduced by $40 \pm 5 \%$ in LMWF-treated animals as compared with vehicle-treated ones $(3 \pm 0.50$ versus $5 \pm 0.30 \mathrm{~mm}^{2}$ respectively, $P<0.01, \mathrm{n}=6$ ). The intima/media ratio was also significantly decreased by $46 \pm 9 \%$ in LMWF-treated animals as compared with vehicle-treated animals $(0.27$ \pm 0.04 versus $0.50 \pm 0.08, P<0.01, \mathrm{n}=6$ ). Cell density was decreased by $30 \pm 5 \%$ in LMWFtreated animals as compared with vehicle-treated animals $\left(28 \pm 4\right.$ versus $40 \pm 3$ cell $/ \mathrm{mm}^{2}$, respectively, $P<0.01, \mathrm{n}=6$ ) (Table 1). The decrease of VSMC proliferation was confirmed by 


\subsection{Antagonistic effects of LMWF on migration and proliferation of human vascular endothelial} and smooth muscle cells

In order to determine the cellular and molecular mechanisms underlying the effects of LMWF in reducing the intimal hyperplasia, we explored its influence on cell growth, spreading and migration of both, human endothelial and vascular smooth muscle cells in vitro.

The proliferative activity of HUV-EC-Cs and VSMCs was quantified after $24 \mathrm{~h}$ of cell incubation with LMWF, using MTT assay. No cell toxicity was observed even at high LMWF dose (100 $\mu \mathrm{g} / \mathrm{ml}$ ) in both cell types (data not shown). LMWF increased significantly the number of viable HUV-EC-Cs in a dose-dependent manner reaching a maximum at $10 \mu \mathrm{g} / \mathrm{ml}$, compared with untreated cells $(40 \pm 4 \%$ increase, $P<0.05, \mathrm{n}=3$ ) (Fig. 2a). Similarly, the number of BrdU- 
positive HUV-EC-Cs, treated with $10 \mu \mathrm{g} / \mathrm{ml} \mathrm{LMWF}$ for $24 \mathrm{~h}$, increased by $25 \pm 8.1 \%$ compared to untreated cells after BrdU incorporation $(P<0.05)$ (data not shown).

LMWF had no significant effect on the number of viable VSMCs, whatever the concentration used (Fig. 3a) using MTT assay. However, the number of BrdU-positive VSMCs, treated with 10 $\mu \mathrm{g} / \mathrm{ml}$ LMWF for $24 \mathrm{~h}$, decreased by $35 \pm 9.9 \%$ compared to untreated cells after BrdU incorporation $(P<0.05)$ (data not shown).

We then addressed the effects of LMWF on spreading and migration of both cell types in vitro. Cells were allowed to spread on fibronectin and then observed by fluorescent microscopy 2 $\mathrm{h}$ after cell incubation with LMWF at increasing concentrations $(0.1,1,10 \mu \mathrm{g} / \mathrm{ml})$. As shown in Fig. 2b, HUV-EC-C spreading was significantly increased by $22.5 \pm 4 \%$ when cells were incubated with $10 \mu \mathrm{g} / \mathrm{ml} \mathrm{LMWF}$ as compared with untreated cells $(P<0.05, \mathrm{n}=3)$. However, LMWF was devoid of effect on VSMC spreading in the same experimental conditions whatever the concentrations used (Fig. 3b).

Two experimental approaches were used to explore the influence of LMWF treatment on cell mobility. In the wound migration assay, LMWF significantly increased HUV-EC-C migration in a dose-dependent manner up to $45 \pm 5 \%$ (at $10 \mu \mathrm{g} / \mathrm{ml} \mathrm{LMWF}$ ) as compared with untreated cells $(P<0.01, \mathrm{n}=3)$ (Fig. 2c). In contrast, LMWF decreased significantly VSMC migration in a dose-dependent manner up to $40 \pm 3 \%$ (at $10 \mu \mathrm{g} / \mathrm{ml}$ LMWF) as compared to untreated cells $(P<$ $0.01, \mathrm{n}=3)$ (Fig. 3c).

Furthermore, the data described above on cell mobility were confirmed by the use of a Boyden chamber approach. Indeed, when upper chambers were coated with Matrigel (referred to as "invasion assay" in Fig. 2d), the ability of HUV-EC-Cs incubated with LMWF to invade through the reconstituted extracellular matrix is 7.5 -fold higher than that of untreated cells at 10 


\subsection{LMWF modulates MMP-2 activity in HUV-EC-Cs and VSMCs}

To analyze the molecular mechanisms underlying the effects of LMWF on HUV-EC-C and VSMC migration, we investigated whether this sulfated polysaccharide could have an influence on MMP-2 level and activity. Fucoidan cell treatment induced an increase in the level of mRNA encoding for MMP-2 in HUV-EC-Cs up to $40 \pm 3 \%$ at $10 \mu \mathrm{g} / \mathrm{ml} \mathrm{LMWF}(P<0.05)$ (Fig. 4a). As shown in Fig. 4b, we also demonstrated using an ELISA assay that the level of total MMP-2 in the conditioned medium from HUV-EC-Cs pre-incubated with $10 \mu \mathrm{g} / \mathrm{ml}$ LMWF for 24 h was increased by 5.4 -fold as compared with untreated cells $(P<0.01, \mathrm{n}=3)$. Furthermore, pro-MMP-2 expression detected by gelatin zymography was also significantly increased by 3.2fold in the conditioned medium from cells treated with $10 \mu \mathrm{g} / \mathrm{ml} \mathrm{LMWF}$ as compared to 
untreated cells (Fig. 4c) $(P<0.01, \mathrm{n}=3)$. This result was confirmed by Western blot (up to 2.5fold increase at $10 \mu \mathrm{g} / \mathrm{ml}$ LMWF) $(P<0.01)$ (Fig. 4d). These data suggest that LMWF increased MMP-2 expression in HUV-EC-Cs at both transcriptional and translational levels.

In contrast, $10 \mu \mathrm{g} / \mathrm{ml}$ LMWF significantly decreased MMP-2 mRNA level in VSMCs by $20 \pm 5 \%$ as compared to untreated cells $(P<0.05)$ (Fig. 5a). Furthermore, the incubation of VSMCs with $10 \mu \mathrm{g} / \mathrm{ml}$ LMWF resulted in a 6-fold decrease in total MMP-2 level in the conditioned medium $(P<0.01, \mathrm{n}=3)$ (Fig. 5b). This result was strengthened by gelatin zymography where pro-MMP-2 expression in LMWF-incubated VSMCs was reduced by about 3-fold at $10 \mu \mathrm{g} / \mathrm{ml} \operatorname{LMWF}(P<0.01, \mathrm{n}=3$ ) (Fig. 5c). This result was also confirmed by Western blot (up to $40 \pm 8 \%$ decrease for $10 \mu \mathrm{g} / \mathrm{ml} \mathrm{LMWF}, P<0.05, \mathrm{n}=3$ ) (Fig. $5 \mathrm{~d}$ ).

MMPs have been demonstrated to be involved in cell migration. Therefore, in order to demonstrate a causal link between LMWF effects on HUV-EC-C and VSMC migration and MMP-2, MMP-2 RNA interference assays were carried out. When HUV-EC-Cs were transfected with MMP-2 siRNA-1 or MMP-2 siRNA-2, MMP-2 mRNA expression was inhibited by $60 \pm$ $5 \%$ or $70 \pm 7 \%$ respectively as compared to control SNC RNA-transfected cells (data not shown). The decrease in MMP-2 mRNA expression was similar in siRNA-2 MMP-2-transfected VSMCs while no significant effect was observed with siRNA-1 MMP-2 (data not shown). As assessed by the wound healing assay, migration of cells transfected with MMP-2 siRNA-1 or MMP-2 siRNA2 was decreased by $50 \pm 5 \%$ or $60 \pm 5 \%$ respectively as compared to SNC RNA-transfected cells $(P<0.01, \mathrm{n}=3)$ (Fig. 6a). The migration of MMP-2 siRNA-1 or MMP-2 siRNA-2-transfected cells induced by LMWF was inhibited by $57.9 \pm 4 \%$ or $60.8 \pm 7 \%$ when compared with SNC RNA-transfected cells (Fig. 6a). In addition, migration of VSMCs transfected with MMP-2 siRNA-2 was decreased by $45 \pm 5 \%$ as compared to SNC RNA-transfected cells $(P<0.01, \mathrm{n}=3)$ (Fig. 6b). In this experimental condition, the migration of LMWF-treated MMP-2 siRNA-2- 


\section{Discussion}

Restenosis of the treated vessel is a common limitation of endovascular procedures and is one of the causes of recurrence of clinical symptoms after revascularization. Restenosis is closely related to neo-intima formation which is a complex process, classically believed to be the consequence of vascular smooth muscle cell proliferation and migration and the synthesis of extracellular matrix [31]. Recently, it has been proposed that the neo-intimal lesion also consists of progenitor cells attracted to the site of injury [32]. In this report, we provide evidences that LMWF treatment prevents the formation of intimal hyperplasia in rat injured thoracic aorta, since 
the thoracic aorta intima/media ratio was largely decreased (46\%) in LMWF-treated rats as compared to vehicle-treated rats. Fucoidan is a sulfated polysaccharide present in brown algae belonging mainly to Fucales and Laminariales orders. Although much effort has been made during the past years to elucidate the structures of sulfated polysaccharides such as heparin and fucoidan, the structural complexity with respect to glycosidic linkage and sulfate position are still limitations to correlate the structures and biological activities of these polysaccharides. It is however established that fucoidan biological activities rely on the sulfate groups, and it is assumed that the recognition of a particular pattern of sulfation may allow specific interaction with targeted proteins. Nevertheless, reduced into low molecular weight fractions, fucoidans have been used for in vivo animal studies. Fucoidan is often presented as a heparin-like molecule due to its ability to interact with several cytokines (growth factors, chemokines) and to exert direct or indirect modulating effect upon their biological activity. Fucoidan is of a particular pharmacological interest because, in addition to its non-animal origin, it exhibits various biological effects, among them anti-inflammatory activities and low anti-coagulant and antithrombotic activities [33,34]. Fucoidans are known to bind growth factors, such as FGFs, and protect them from proteolysis [33]. Fucoidans can release the glycosaminoglycan-bound SDF1/CXCL12 from its tissue storage sites and can also bind to this chemokine [17,34].

Our results obtained from an in vivo rat model are in accordance with previous studies which demonstrated that fucoidans could reduce intimal hyperplasia. Indeed, it was previously reported that LMWF prevents neo-intimal formation in a rabbit model of in-stent restenosis in iliac artery [14] or after aortic allograft in rats [32]. LMWF promotes therapeutic revascularization in a rat model of critical hindlimb ischemia $[15,35]$. Our data also suggest that LMWF increases vascular endothelial cell proliferation, spreading and migration, but decreases vascular smooth muscle cell migration. These data agree with previous in vitro and in vivo studies [14,36,37]. The molecular 
mechanisms by which fucoidans may inhibit the neo-intima formation are multiple: On the one hand, fucoidans, especially LMWF, promote growth factor effects, such as FGF-2 [15,33] or VEGF [38] leading to neovascularization. The proposed mechanism is therefore that fucoidans may act in vivo by trapping and protecting endogenously released growth factors from deactivation and proteolytic cleavage or may also displace endogenous growth factors from their tissue heparan sulfate storage sites thus increasing their bioavailability. However, LMWF was also demonstrated to have therapeutic effects in angiogenesis on its own, since a beneficial effect in revascularization was reported with LMWF alone in vivo [39]. On the other hand, another reported effect of fucoidans is the ability to promote progenitor stem cell mobilization via the release of the chemokine SDF-1/CXCL12 from heparan sulfate storage sites [34]. SDF1/CXCL12 is involved in angiogenesis [40] and regulates endothelial cell branching morphogenesis [41].

Although most therapeutic strategies to prevent restenosis are designed to inhibit VSMC proliferation directly, VSMC proliferation might be indirectly inhibited by re-endothelialization, as endothelial cells secrete antiproliferative and antithrombotic substances [42]. Recently, a strategy using in vivo gene transfer of human Hepatocyte Growth Factor that exclusively stimulated endothelial cells without replication of VSMC growth into injured vessels, results in the successful inhibition of neo-intima formation in rat balloon injured carotid artery [42]. It was also demonstrated in post-angioplasty intimal hyperplasia that active vascular endothelial cells participate in the secretion of growth factors for vascular smooth muscle cells [43] and contribute to the pro-inflammatory response through the secretion of cytokines. In addition, active vascular endothelial cells increase VSMC migration by elaborating factors like platelet-derived growth factor and alter VSMC adhesion molecule expression. Thereafter, the interrelations between vascular endothelial and smooth muscle cells may play a major role in the neo-intima 
development. In that context, our data demonstrated that conditioned medium from vascular endothelial cells induces the migration across fibronectin of vascular smooth muscle cells. Interestingly, this induction is largely reduced when using conditioned medium from vascular endothelial cells pre-incubated with LMWF. Strikingly, LMWF in unconditioned HUV-EC-C culture medium, placed in the lower part of the Boyden chamber, induced slightly VSMC migration as compared to control unconditioned HUV-EC-C medium. This data suggests that in these experimental conditions, LMWF potentializes the migratory effects of growth factors present in the unconditioned culture medium, such as VEGF, as described [38]. In contrast, conditioned medium of HUV-EC-Cs pre-treated with LMWF reduced the migration of VSMCs as compared to conditioned medium of untreated HUV-EC-Cs, suggesting that LMWF may reduce the level of vascular endothelial cell-secreted molecules able to induce VSMC migration or may interfere with them and inhibit their chemotactic effects on VSMCs.

In the present study, in situ zymography revealed that LMWF significantly decreases MMP-2 activity in the neo-intima. According to the in vitro study, LMWF increases MMP-2 protein expression and activity in HUV-EC-Cs. In contrast, a decrease in MMP-2 protein expression and activity is observed in VSMCs. Furthermore, the level of total MMP-2 in the conditioned medium from cells incubated with $10 \mu \mathrm{g} / \mathrm{ml}$ LMWF was 5.4-fold higher in HUVEC-Cs, but 6-fold lower in VSMCs than in untreated controls cells. The remodelling of the vascular wall in response to injury critically depends on the action of extracellular proteases, such as the MMPs, and is accompanied by the migration of VSMCs [29]. This enzyme family consists of a number of structurally related proteinases capable of degrading ECM proteins, including basement membrane collagen, denatured collagen (gelatin), laminin, various proteoglycans and elastin [44]. Previous studies have shown that the MMP expression or activation is upregulated in human atherosclerotic lesions and in rat arteries after balloon catheter injury [31]. Increased pro- 
MMP-9, MMP-2 and pro-MMP-2 activities were detected at 1-st, 3-rd and 7-th days after arterial injury, respectively in rabbit model of intimal hyperplasia [31]. Sweeney et al. [17] also indicated that plasma MMP-9 significantly increased after intravenous injection of HMW fucoidan. In contrast, LMWF did not induce an increase in MMP-9 level in vivo. It was also demonstrated that fucoidan significantly inhibited UVB-induced MMP-1 mRNA expression in a dosedependent manner [45]. In addition, peptide-based inhibitors of MMP activity have been shown to block VSMC migration [46]. Our data demonstrate that LMWF increase MMP-2 expression at both transcriptional and translational levels, as well as MMP-2 activity. Furthermore, our results suggest a direct linkage between LMWF and MMP-2, since MMP-2 downregulation by RNA interference affects LMWF-induced effects on cell migration in vitro. The precise molecular mechanisms of action of LMWF in various cells are in most cases unknown. It was demonstrated that fucoidan can enter into cells through a endocytosis pathway [14] and regulate various signalling pathways $[45,47]$. Our data hypothesize that LMWF could reduce intimal hyperplasia through the modulation of MMP-2 expression in various cell types involved in the neo-intima development. In vascular endothelial cells, LMWF would increase MMP-2 expression while decreasing it in VSMCs and leading to antagonist effect on cell migration, enhanced for endothelial and reduced for VSMCs.

In summary, our data highlight the protective effects of fucoidans on the undesired formation of neo-intima after balloon injury and propose a new underlying mechanism besides the known effect of fucoidans on growth factor activities and the promotion of progenitor stem cell mobilization via the release of the chemokine SDF-1/CXCL12. Other LMW heparin preparations have already shown properties similar to cellular effects induced by LMWF $[14,37]$. Nevertheless, LMWF exhibit lower anticoagulant activity [13] and a rapid degradation of internalized heparin in VSMCs has been observed conversely to LMWF [37]. 


\section{Acknowledgments}

This work was supported by the Direction de la Recherche et des Enseignements Doctoraux (Ministère de 1'Enseignement Supérieur et de la Recherche), the University Paris 13 and INSERM. N. Suffee was supported by a fellowship from Ministère de l'Enseignement Supérieur et de la Recherche. The authors would like to thank Liliane Louedec (INSERM U698) for her technical assistance with the animal experiments. 


\section{References}

\section{Figure legends}

Fig. 1. LMWF reduced intimal hyperplasia after balloon injury in rat thoracic aorta.

(a). Representative micrographs show histological cross-sections of uninjured (left panel), balloon-injured and vehicle-treated (middle panel) or balloon-injured and LMWF-treated (right panel) rat aorta staining in hematoxylin and eosin. Dotted line indicates the basal membrane defining the limit between the neo-intima and the media. n, neo-intima; m, media. Magnification, X10. Insets show at higher magnification the intima layer. (b). PCNA (red) immunostaining in uninjured (left panel), balloon-injured and vehicle-treated (middle) or balloon-injured and LMWF-treated (right panel) rat aortas. Magnification, X30. n, neo-intima; m, media. The green fluorescence corresponds to autofluorescence of the elastic lamina (c). Cell types were characterized by immunofluorescence staining with anti-CD31 mAbs for endothelial cells (red), mouse anti-human smooth-muscle $\alpha$-actin ( $\alpha$-SMA) mAbs (green), DAPI (blue) for nucleus and merged for anti-CD31 mAb/DAPI (red/blue) of injured aortas. Magnification, X20. White dotted line indicated the basal membrane defining the limit between the neo-intima and the media. $\mathrm{n}$, neo-intima; m, media.

Fig. 2. LMWF increased HUV-EC-C proliferation, spreading, migration and invasion. HUV-EC-Cs were either untreated or incubated with LMWF (at $0.1,1$ or $10 \mu \mathrm{g} / \mathrm{ml}$ ) and were assessed for viability (a), spreading (b), wound healing (c) or for invasion assay (d). 
(a). For viability MTT assay, the results for three independent experiments were expressed as percentage of control cells without LMWF treatment. The number of viable untreated cells was arbitrary set to $100 \% .^{*}, P<0.05$ versus untreated cells.

(b). For spreading assay, the cells were incubated with LMWF at the indicated concentrations $(0.1,1$ or $10 \mu \mathrm{g} / \mathrm{ml})$, allowed to spread on fibronectin for $2 \mathrm{~h}$, and stained with Alexa Fluor 546 phalloidin. They were observed under a fluorescence microscope (lower panel), photographed and theirs areas were evaluated by NIH (release Beta 3b) software (upper panel, histograms). The results for three independent experiments were expressed as percentage of control cells without LMWF treatment. The spreading of untreated cells was arbitrary set to $100 \%$. Bar=5 $\mu \mathrm{m}$. ${ }^{*}, P<$ 0.05 versus untreated cells.

(c). Wound migration assay was performed with a monolayer of HUV-EC-Cs, either untreated or incubated with LMWF at the indicated concentrations. Lower panel: Representative phase contrast photographs were taken $48 \mathrm{~h}$ after treatment. Bar $=200 \mu \mathrm{m}$. Upper panel: Histograms showing HUV-EC-C wound migration in each condition. The results were expressed in mm of cell displacement. The data are expressed as mean \pm SEM. * $P<0.05$ versus untreated cells; **, $P<0.01$ versus untreated cells.

(d). In the cell invasion assay (Boyden chamber), cells, incubated with $0.1,1$ or $10 \mu \mathrm{g} / \mathrm{ml} \mathrm{LMWF}$ and migrated through the Matrigel-coated membrane, were stained with Mayer's hemalum and counted. The results are expressed as cell number per field. The datas are expressed as mean + SEM for three independent experiments. ${ }^{*}, P<0.05$ versus untreated cells; ${ }^{* *}, P<0.01$ versus untreated cells.

\section{Fig. 3. LMWF decreased VSMC migration and invasion.}


VSMCs were either untreated or incubated with LMWF (at $0.1,1$ or $10 \mu \mathrm{g} / \mathrm{ml}$ ) and were assessed for viability (a), spreading (b), wound healing (c), invasion (d) or for migration assay (e).

(a). For viability MTT assay, the results for three independent experiments were expressed as percentage of control cells without LMWF treatment. The number of viable untreated cells was arbitrary set to $100 \%$.

(b). The cells were incubated or not with $0.1,1$ or $10 \mu \mathrm{g} / \mathrm{ml}$ LMWF and assayed for spreading. Photographs were taken under a fluorescence microscope (lower panel) and the cell areas were evaluated by NIH (release Beta 3b) software (upper panel, histograms). The results for three independent experiments were expressed as percentage of control cells without LMWF treatment. The spreading of untreated cells was arbitrary set to $100 \%$. Bar $=5 \mu \mathrm{m}$.

(c). Wound migration assay was performed with a monolayer of VSMCs, either untreated or incubated with LMWF at the indicated concentrations. Lower panel: Representative phase contrast photographs were taken $48 \mathrm{~h}$ after treatment. Bar $=150 \mu \mathrm{m}$. Upper panel: Histograms showing VSMC wound migration in each condition. The results were expressed in mm of cell displacement. The data are expressed as mean \pm SEM. $*, P<0.05$ versus untreated cells; $* *, P<$ 0.01 versus untreated cells.

(d). In the cell invasion assay (Boyden chamber), cells, incubated with $0.1,1$ or $10 \mu \mathrm{g} / \mathrm{ml} \mathrm{LMWF}$ and migrated through the Matrigel-coated membrane were stained with Mayer's hemalum and counted. The results are expressed as cell number per field. The datas are expressed as mean + SEM for three independent experiments. ${ }^{*}, P<0.05$ versus untreated cells; ${ }^{\S}, P<0.001$ versus untreated cells.

(e). VSMCs migrated across fibronectin towards conditioned medium from HUV-EC-Cs either untreated or pre-incubated with $10 \mu \mathrm{g} / \mathrm{ml} \mathrm{LMWF}$. The results are expressed in cell number per field. The datas are expressed as mean + SEM for three independent experiments. ${ }^{*}, P<0.05$ for 
unconditioned medium in the presence of LMWF versus unconditioned medium; ${ }^{\S}, P<0.001$ for HUV-EC-C conditioned medium versus unconditioned medium; $* *, P<0.01$ for conditioned medium from HUV-EC-Cs pre-treated with LMWF versus conditioned medium from untreated HUV-EC-Cs.

\section{Fig. 4. LMWF increased MMP-2 expression in HUV-EC-Cs.}

HUV-EC-Cs were either untreated or incubated with 1 or $10 \mu \mathrm{g} / \mathrm{ml} \mathrm{LMWF}$ for $24 \mathrm{~h}$.

(a). LMWF increased the level of mRNA encoding for MMP-2 in HUV-EC-Cs as assessed by real-time PCR. Results are expressed in arbitrary unit (AU). Data are expressed as mean + SEM. *, $P<0.05$ versus untreated cells. MMP-2 mRNA level was arbitrary set to 1 in untreated cells. (b). Total MMP-2 expression was detected by ELISA assay in the conditioned medium from HUV-EC-Cs either untreated or incubated with $10 \mu \mathrm{g} / \mathrm{ml}$ LMWF. All data are expressed as mean + SEM. $*, P<0.05$ versus untreated cells; $* *, P<0.01$ versus untreated cells.

(c) Lower panel: MMP-2 activity in the cell conditioned medium was assessed by gelatin zymography. Upper panel: Representative histograms of gelatin zymography. Results are expressed in arbitrary unit (AU). All data are expressed as mean + SEM. ${ }^{* *}, P<0.01$ versus untreated cells.

(d). Total MMP-2 protein was detected by Western blot in the conditioned medium from HUVEC-Cs either untreated or incubated with 1 or $10 \mu \mathrm{g} / \mathrm{ml}$ LMWF. Results are expressed in arbitrary unit (AU). All data are expressed as mean + SEM. $* *, P<0.01$ versus untreated cells.

\section{Fig. 5. LMWF decreased MMP-2 expression in VSMCs.}

VSMC cells were either untreated or incubated with 1 or $10 \mu \mathrm{g} / \mathrm{ml} \mathrm{LMWF}$ for $24 \mathrm{~h}$. 
Fig. 6. MMP-2 RNA interference decreased LMWF-induced effects in HUV-EC-Cs or VSMCs.

(a). The migration of HUV-EC-Cs induced by $10 \mu \mathrm{g} / \mathrm{ml}$ LMWF was reduced when cells were transfected with MMP-2 siRNA-1 or MMP-2 siRNA-2 as compared to control SNC RNAtransfected cells. The results were expressed in $\mathrm{mm}$ of cell displacement. The data are expressed as mean \pm SEM. ${ }^{\S}, P<0.01$ versus LMWF-untreated SNC RNA-transfected cells; $*, P<0.05$ versus LMWF-untreated MMP-2- siRNA-1 or siRNA-2-transfected cells; **, $P<0.01$ versus

(a). LMWF decreased the level of mRNA encoding for MMP-2 in VSMCs as assessed by realtime PCR. Results are expressed in arbitrary unit (AU). Data are expressed as mean + SEM. *, $P$ $<0.05$ versus untreated cells. MMP-2 mRNA level was arbitrary set to 1 in untreated cells.

(b). Total MMP-2 expression was detected by ELISA assay in the conditioned medium from VSMCs either untreated or incubated with LMWF. All data are expressed as mean + SEM. *, $P<$ 0.05 versus untreated cells; ${ }^{* *}, P<0.01$ versus untreated cells.

(c). Lower panel: MMP-2 activity was assessed in cell conditioned medium by gelatin zymography. Upper panel: Representative histograms of gelatin zymography. Results are expressed in arbitrary unit (AU). All data are expressed as mean + SEM. *, $P<0.05$ versus untreated cells; ${ }^{* *}, P<0.01$ versus untreated cells.

(d). Total MMP-2 protein was detected by Western blot in the conditioned medium from VSMCs either untreated or incubated with $1 \mathrm{or} 10 \mu \mathrm{g} / \mathrm{ml}$ LMWF. Results are expressed in arbitrary unit (AU). All data are expressed as mean + SEM. *, $P<0.05$ versus untreated cells.

\section{LMWF-untreated SNC RNA-transfected cells.}


(b). The migration of VSMCs induced by $10 \mu \mathrm{g} / \mathrm{ml}$ LMWF was unchanged when cells were transfected with MMP-2 siRNA-2 as compared to control SNC RNA-transfected cells. The results were expressed in mm of cell displacement. The data are expressed as mean \pm SEM. ${ }^{\S}, P<$ 0.01 versus LMWF-untreated SNC RNA-transfected cells; * $P<0.05$ versus LMWF-untreated SNC RNA-transfected cells.

(c). MMP activities were observed in rat injured thoracic aortas by in situ zymography. Representative examples of cross-sections were observed using fluorescence microscopy (blue fluorescence of DAPI nuclear staining, left column; green fluorescence of in situ gelatin lysis by MMPs after in situ zymography, middle column; green fluorescence of in situ gelatin lysis by MMPs after in situ zymography in presence of MMP inhibitor, right column. All pictures are taken with X4 magnification. $\mathrm{n}$, neo-intima; m, media. The arrows indicate the in situ MMP activities in the neo-intima peripheral layer.

\section{Table 1. LMWF significantly reduced intimal hyperplasia}

Treatment with LMWF significantly reduced the neo-intimal and media areas, the intima/media ratio, cell number in neo-intima or media and cell density. The data are expressed as mean + SEM. 


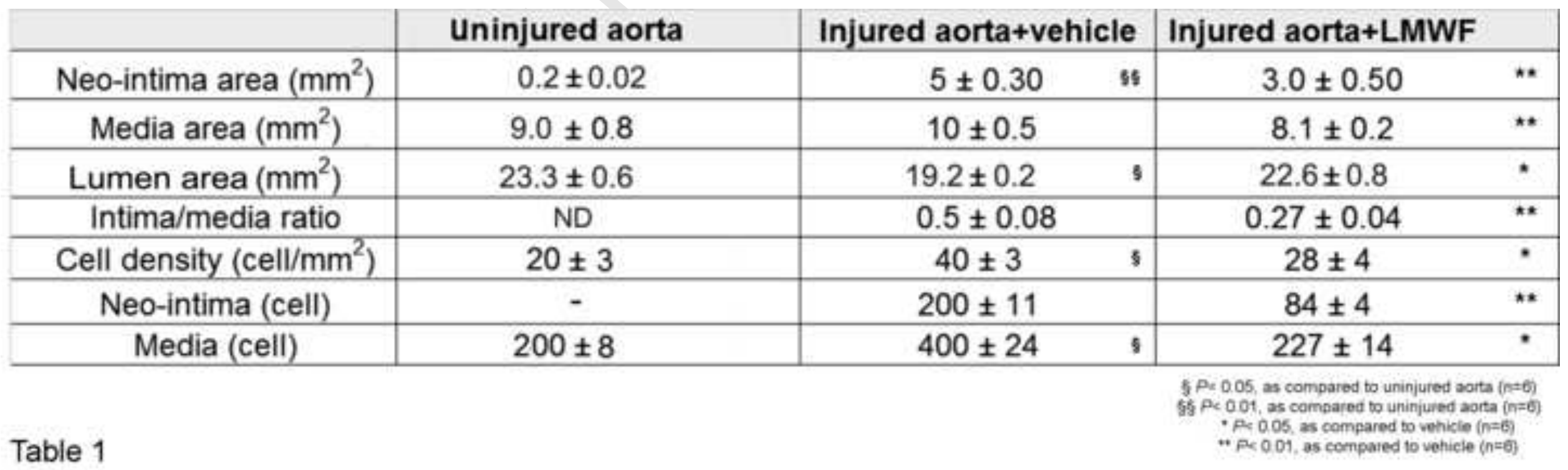




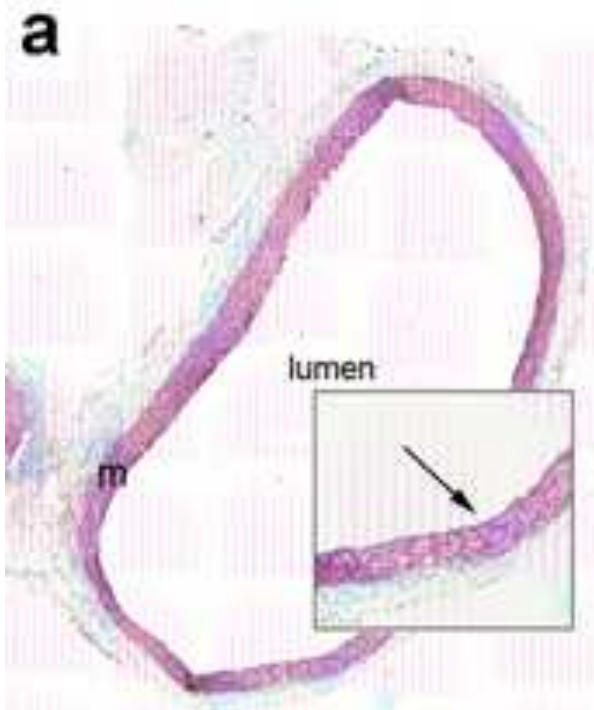

Uninjured aorta

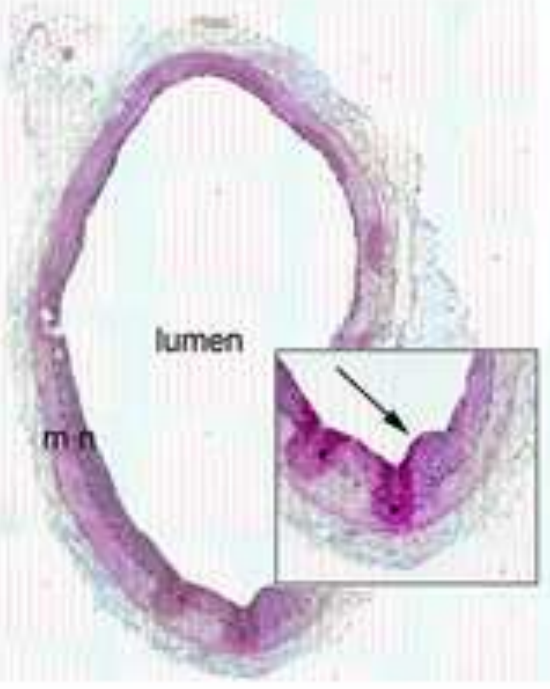

Injured aorta +vehicle treatment

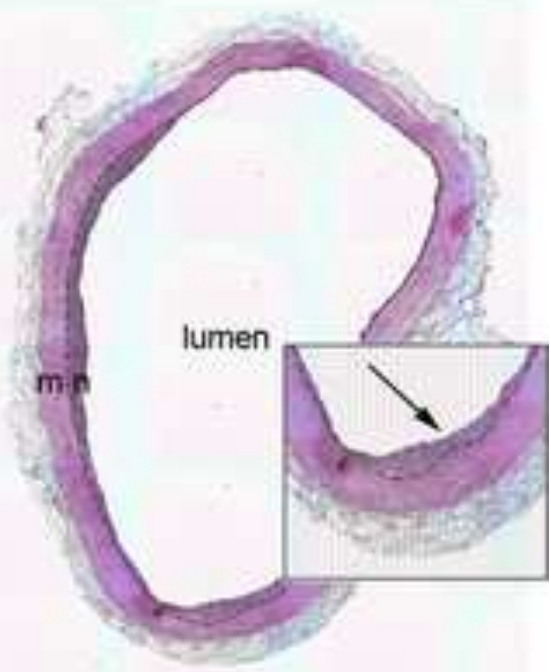

Injured aorta +LMWF treatment

b

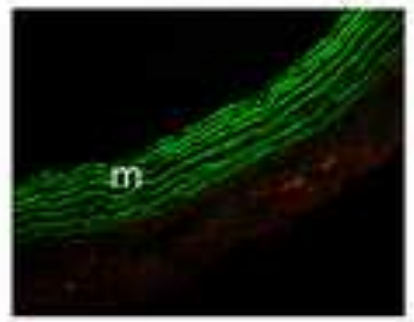

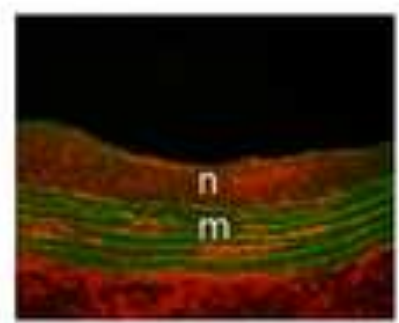

Injured aorta +vehicle treatment

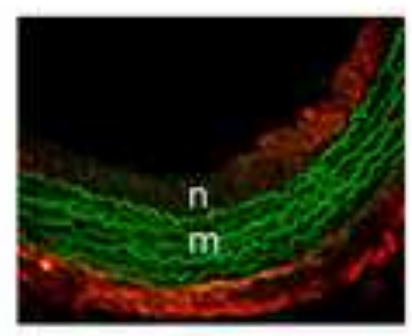

Injured aorta +LMWF treatment

C
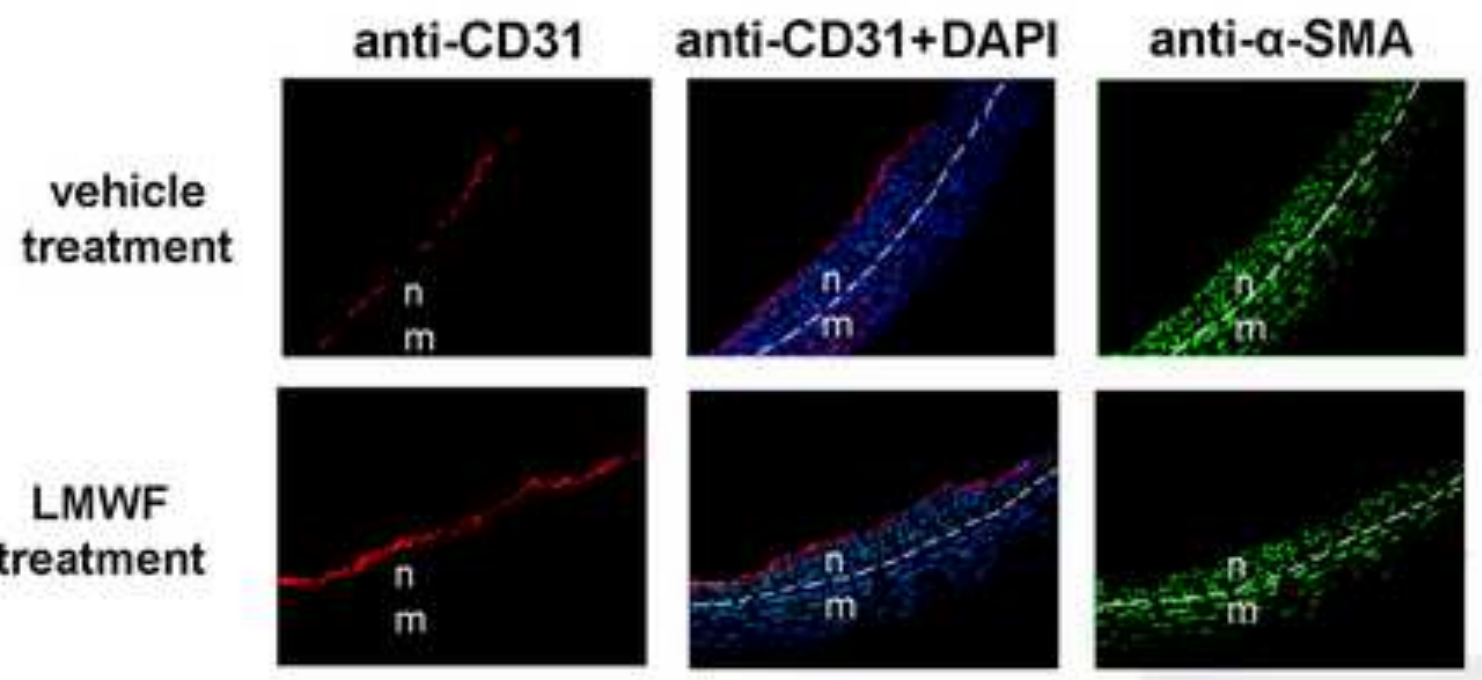

Figure 1 

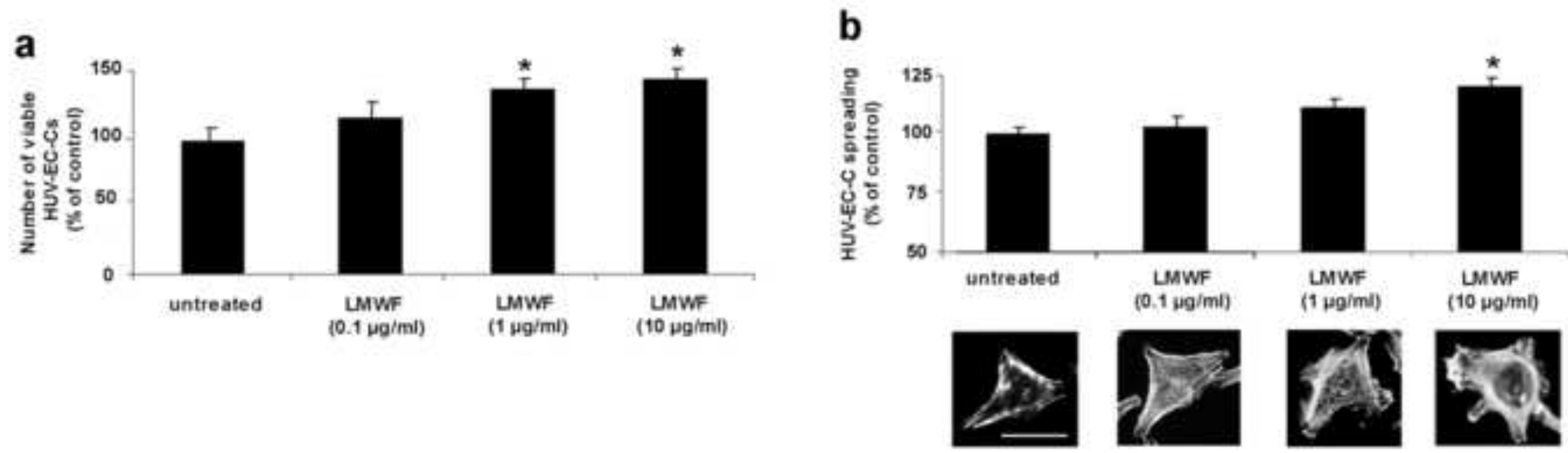

C
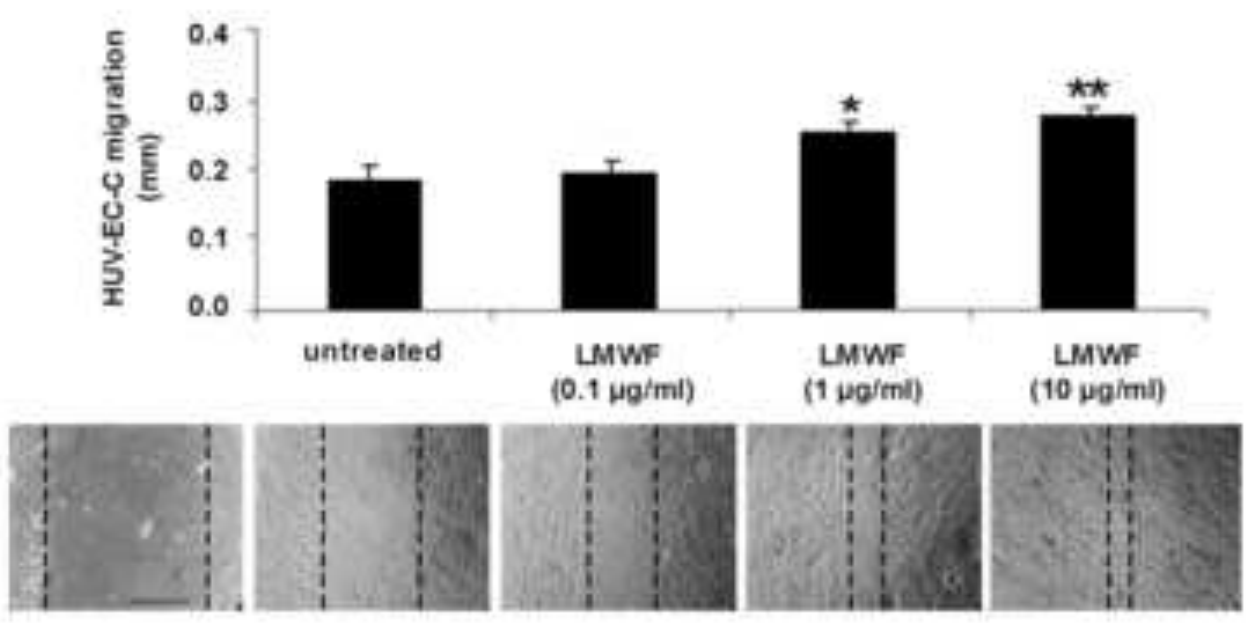

d

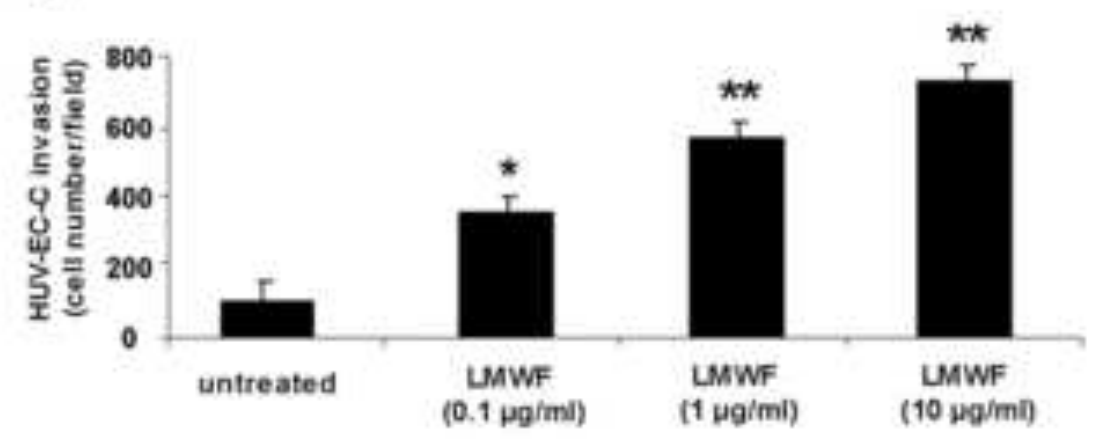

TOh

T48h

Figure 2 
a

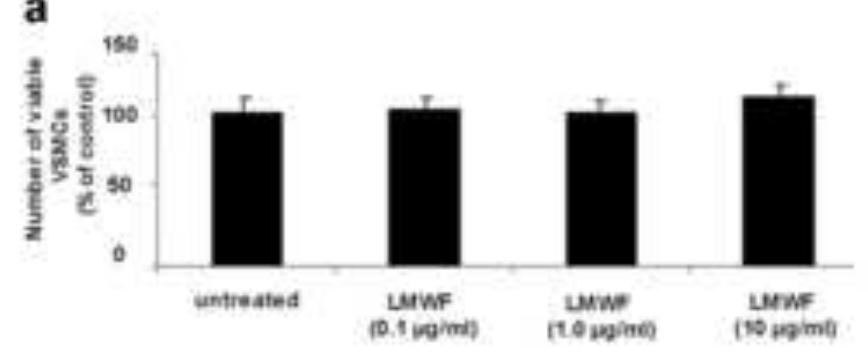

c
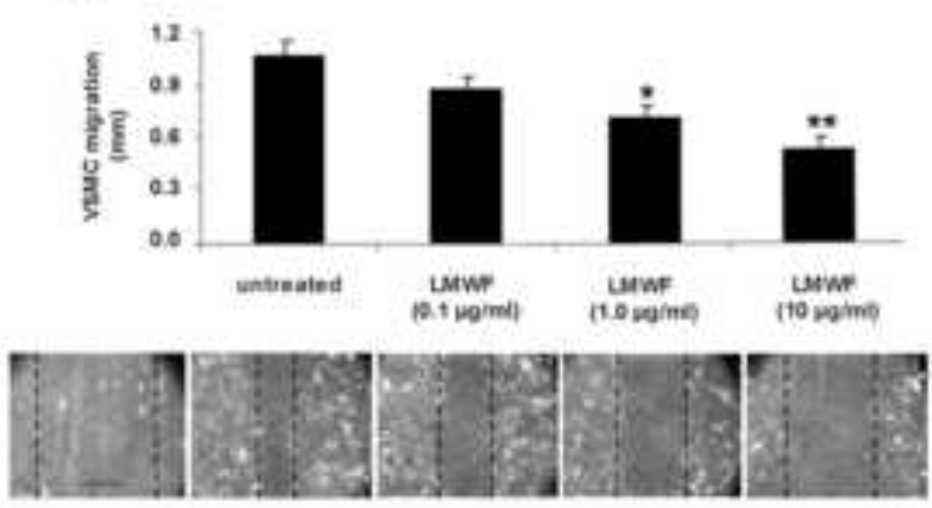

$\tan$

T4m b

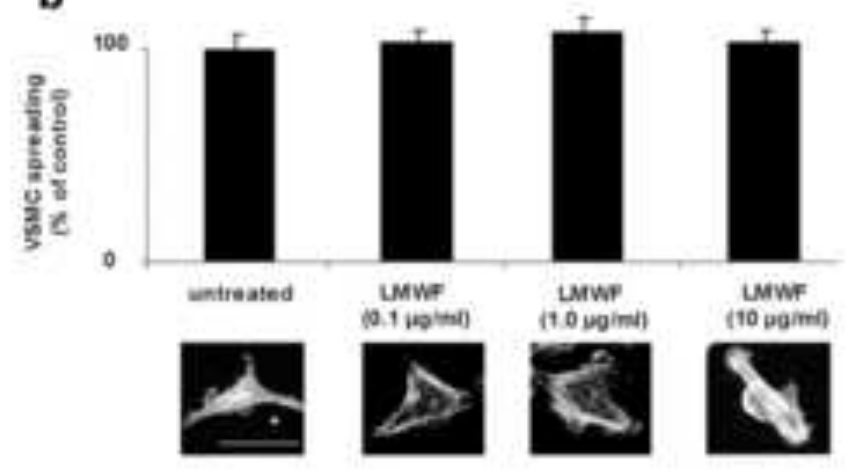

d

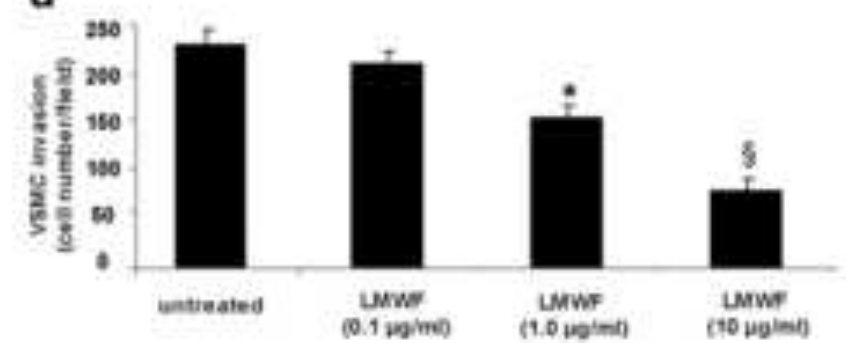

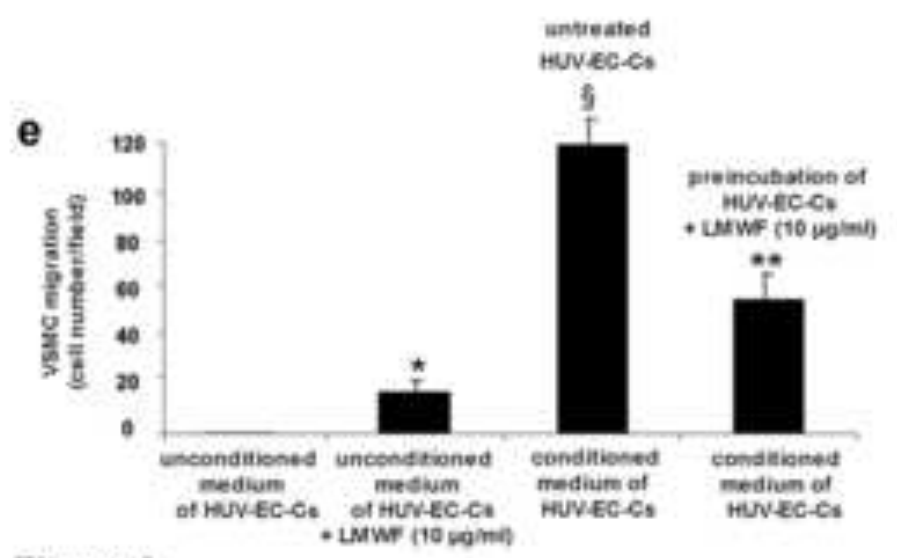

Figure 3 
a

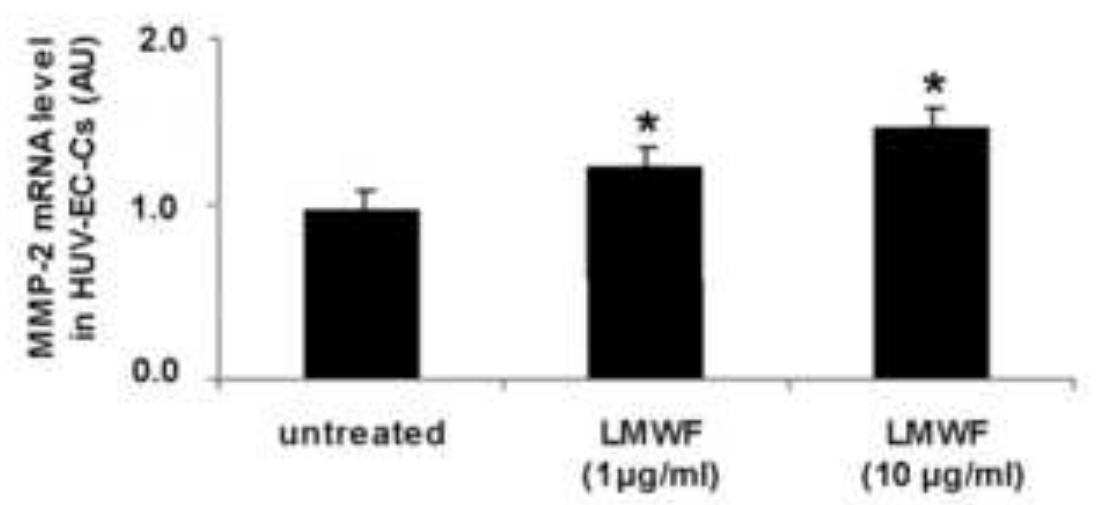

C

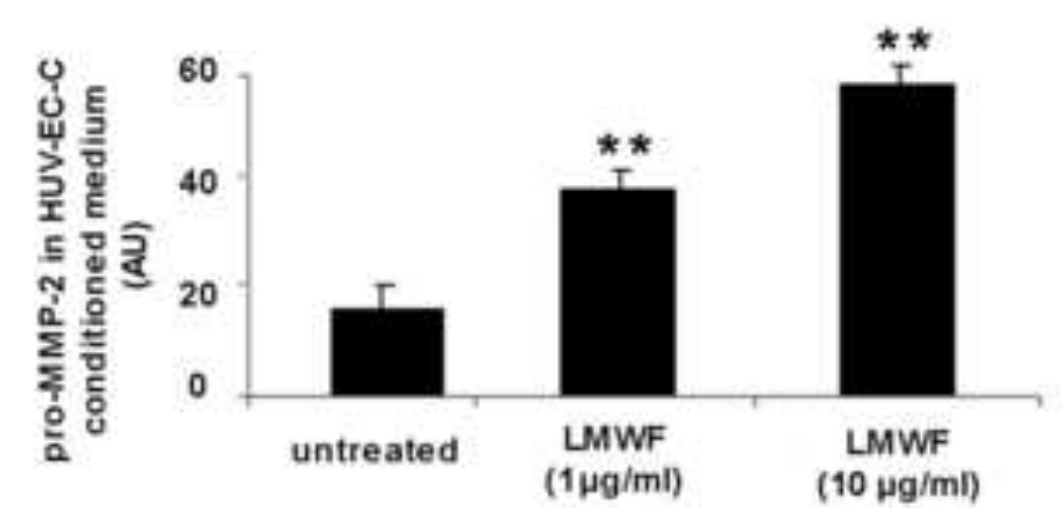

b
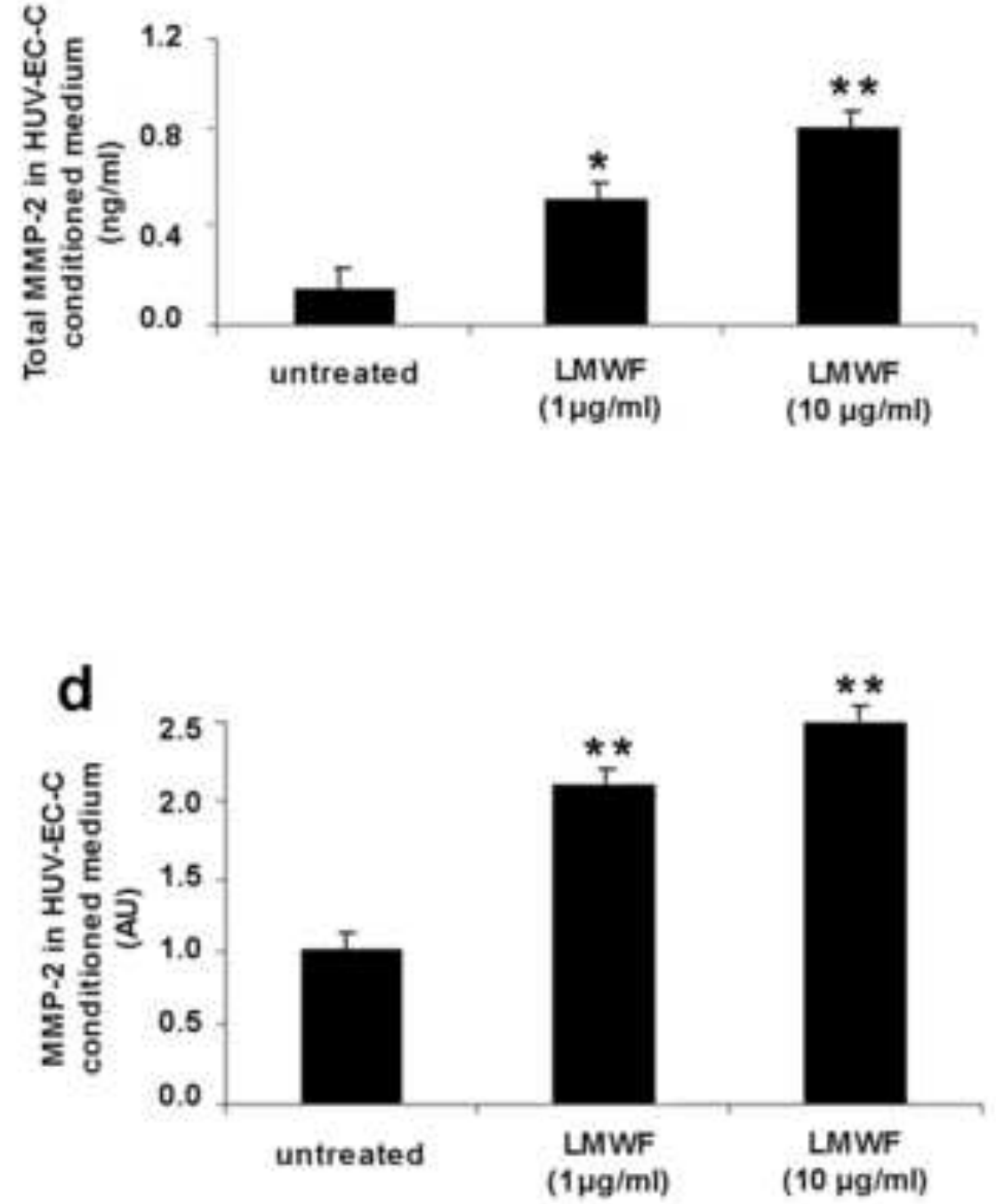

pro-MMP-2 MMP-2

Figure 4 
a

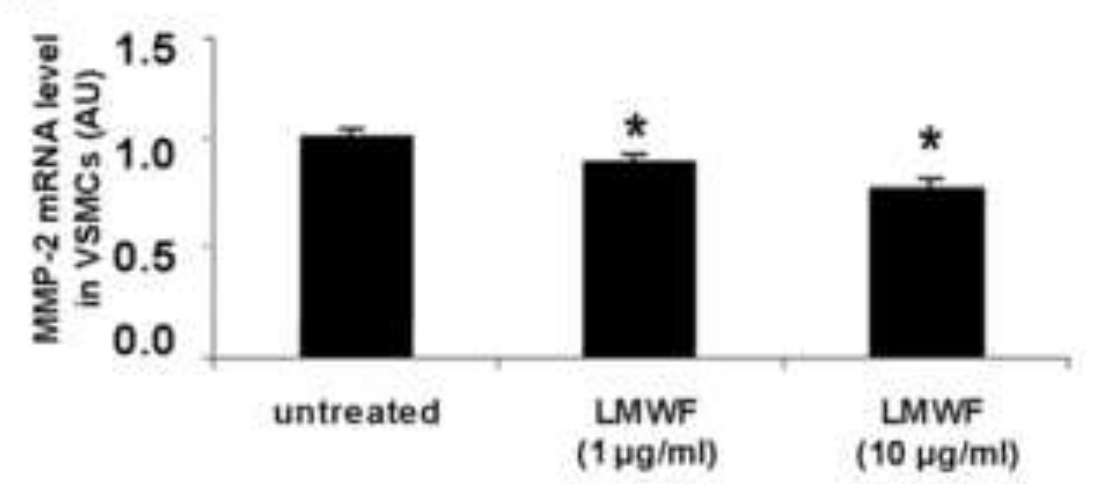

C

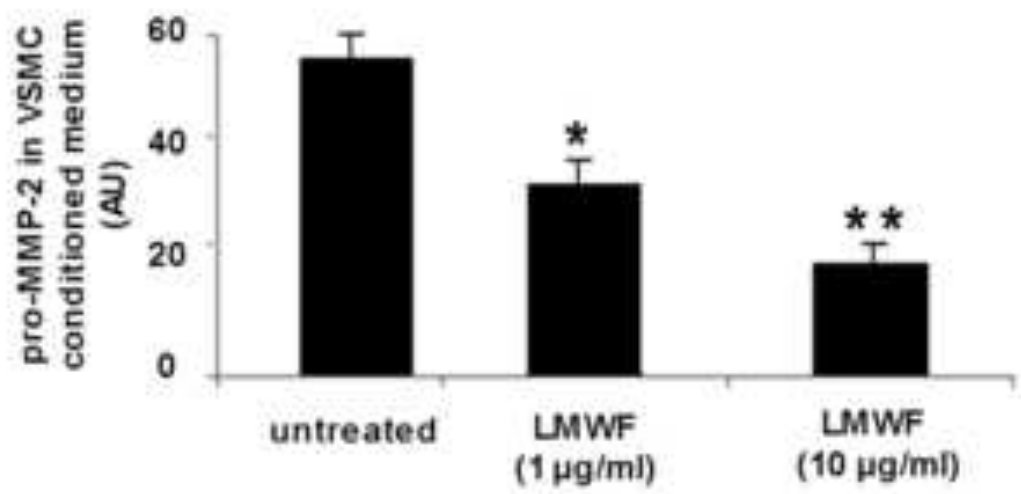

b

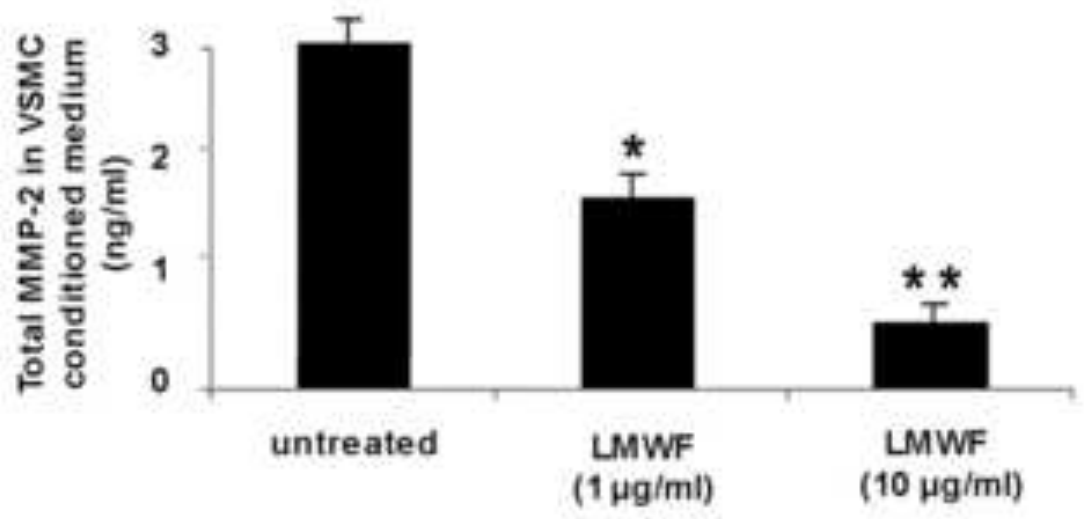

d

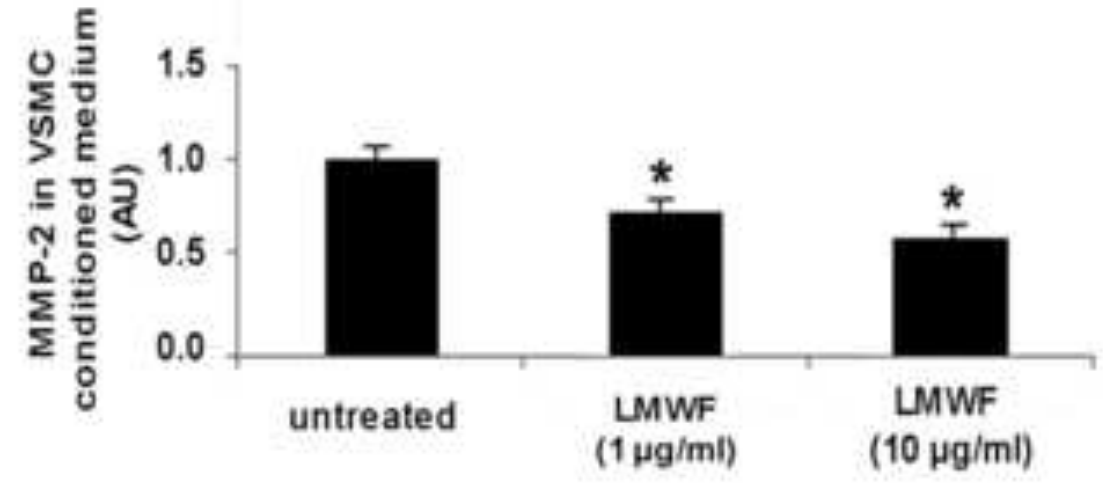

pro-MMP-2 MMP-2

Figure 5 
a
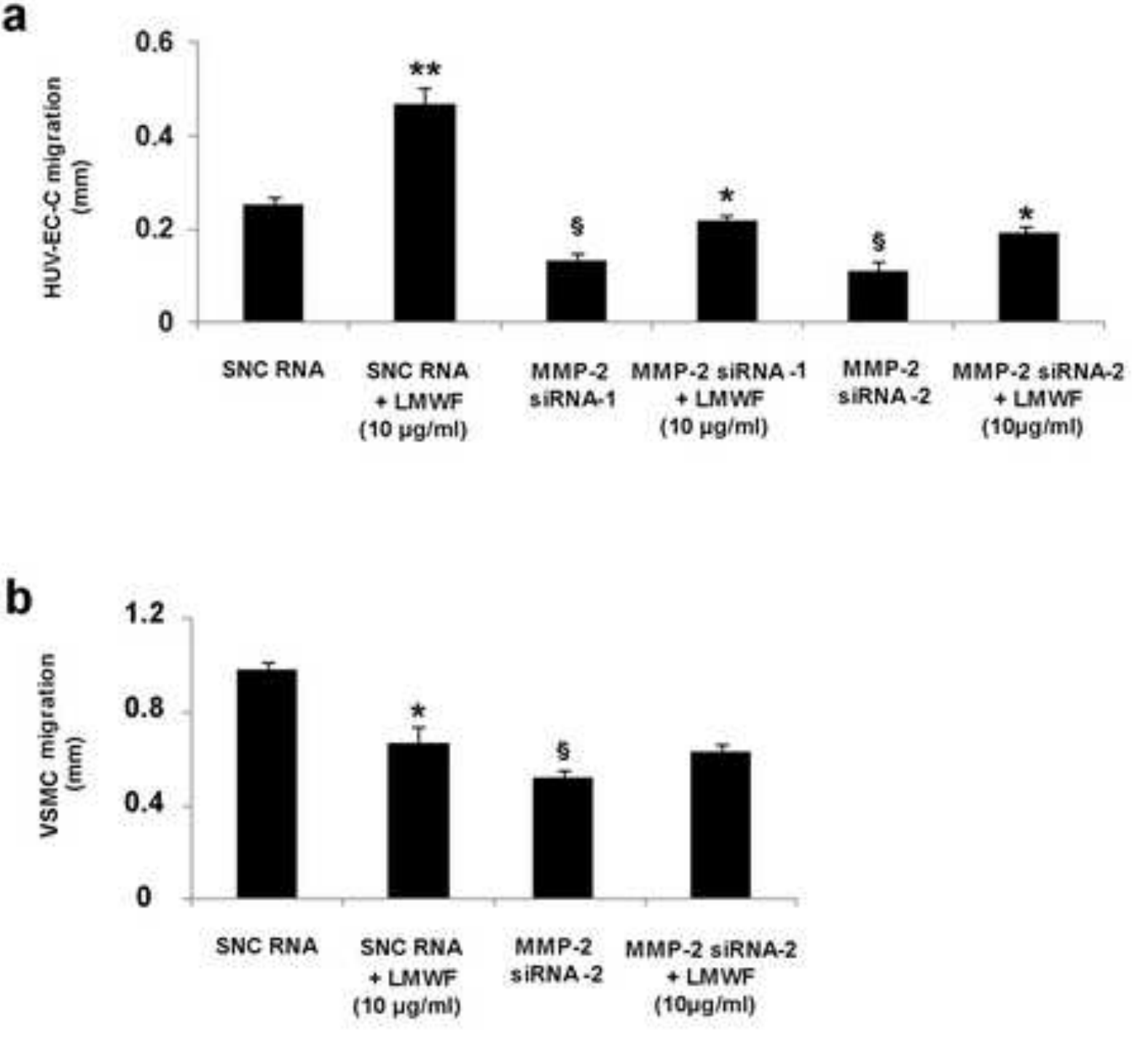

C

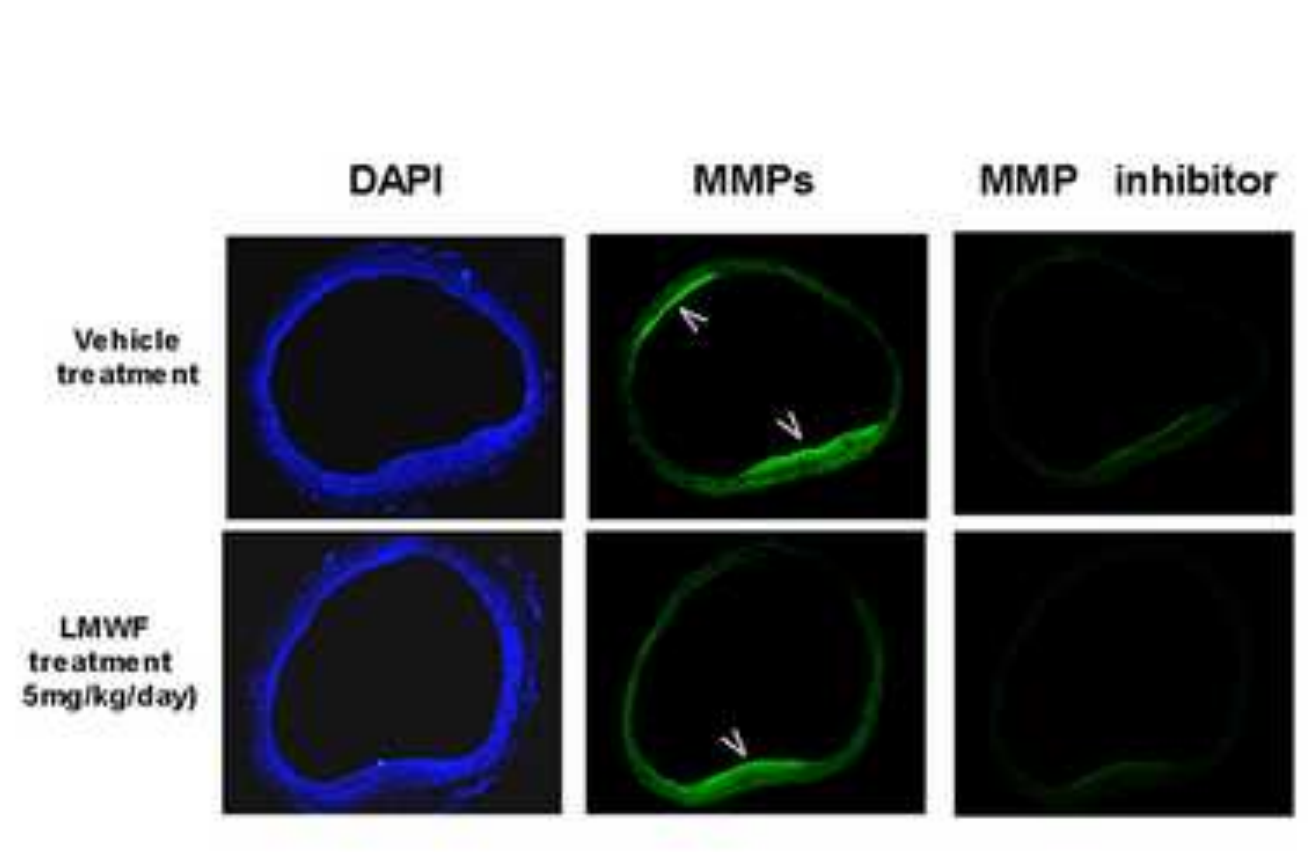

Figure 6

+ LMWF
$(10 \mu g / \mathrm{ml})$

(10 $\mu \mathrm{g} / \mathrm{ml})$

(10, $\mathrm{g} / \mathrm{ml})$

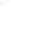

$$
\text { (1) }
$$
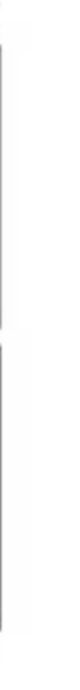

.

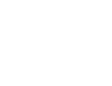

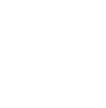

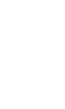



thoracic aorta through the modulation of matrix metalloproteinase-2 expression.

Hlawaty H, Suffee N, Sutton A, Oudar O, Haddad O, Olivier V, Laguillier-Morizot C, Gattegno L, Letourneur D, Charnaux N
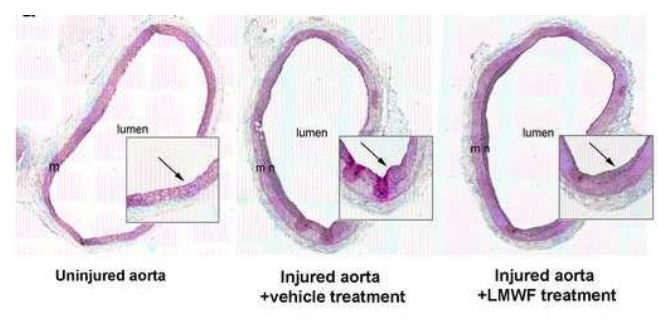